\title{
The Importance of Open Access in Community Obstetrics
}

\section{Aniefiok Jackson Umoiyoho*}

Department of Obstetrics and Gynaecology, College of Health Sciences, University of Uyo, P. M. B. 1017, Uyo, Akwa Ibom State, Nigeria

According to an old adage, education refines a man and transforms him into a better man and the easiest way to educate a man is to make materials in readable form available to him. Making available literary resource has become one of the most effective ways to disseminate information in an easily retrievable format especially in low resource countries. When such materials are made available electronically, its widest publicity knows no bound. The internet provides the medium for this kind of wide dissemination. However, access to such information may be restricted. Open Access publication comes to the rescue in such circumstances.

In Open Access, the article is made universally and freely accessible through the internet in a readable and easily retrievable but agreed form. It is deposited immediately after publication. The authors and copyright owners irrevocably grant the third party in advance and in perpetuity the right to use, reproduce or disseminate the research article in its entirety or in part in any format or medium; provided no substantive errors or alterations are introduced in the process and authorship details are not changed. This is even more important in developing countries where access to published articles may be restricted by financial constraints.

Where a specialty is new, it becomes even more important that new knowledge should be put in the public domain for necessary input, criticism and correction. This is the case with the emerging subspecialty of Community Obstetrics.

Community Obstetrics is a subspecialty of Obstetrics that deals with the care, status and the behaviour of women in a specified community during pregnancy, childbirth and within six weeks of delivery, with the aim of promoting, protecting and preserving the wellbeing of the women. These women in the community may have common characteristics and behavioural pattern that make them different from other women. They can also be defined in terms of their location, race, ethnicity, age, occupation or interest and bond. Thus we can speak of the obstetric status or behaviour of the Annang women of Akwa Ibom State of Nigeria, Chief Executive Officers of companies or teenagers. This will give some insight into the peculiar problems of such women and so help in the planning of their care. This is in keeping with the known norm of different groups posing different problem to their obstetric care. It is therefore instructive to develop this subspecialty so the obstetric parameters of such groups can be investigated in details. This can help in planning for solutions of those problems.

In order to popularise this subspecialty, open access publication becomes very imperative and its importance in this direction cannot be over emphasised.
*Corresponding author: Aniefiok Jackson Umoiyoho, Senior Lecturer/Honorary Chief Consultant, Department of Obstetrics and Gynaecology, College of Health Sciences, University of Uyo, P. M. B. 1017, Uyo, Akwa Ibom State, Nigeria, E-mail: draniiyoho@yahoo.com

Received March 09, 2012; Accepted March 09, 2012; Published March 15, 2012 Citation: Umoiyoho AJ (2013) The Importance of Open Access in Community Obstetrics. J Socialomics 2: e110. doi:10.4172/2167-0358.1000e110

Copyright: () 2013 Umoiyoho AJ. This is an open-access article distributed under the terms of the Creative Commons Attribution License, which permits unrestricted use, distribution, and reproduction in any medium, provided the original author and source are credited. 